\title{
Ultraviolet radiation modulates both constitutive and inducible plant defenses against thrips but is dose and plant genotype dependent
}

\author{
Rocío Escobar-Bravo ${ }^{1}$ (D) Charlotte Nederpel ${ }^{1}$. Sofía Naranjo ${ }^{1} \cdot$ Hye Kyong Kim ${ }^{1}$ • María José Rodríguez-López ${ }^{1}$. \\ Gang Chen ${ }^{1} \cdot$ Gaétan Glauser $^{2} \cdot$ Kirsten A. Leiss $^{1,3} \cdot$ Peter G. L. Klinkhamer ${ }^{1}$
}

Received: 30 May 2019 / Revised: 9 September 2019 / Accepted: 18 October 2019 / Published online: 31 October 2019

(c) The Author(s) 2019

\begin{abstract}
Ultraviolet (UV) radiation has emerged as an environmental cue with potential uses to enhance plant protection against arthropod pests in agriculture. UV can augment constitutive and inducible plant defenses against herbivorous arthropods. Here we investigated whether application of supplemental UV to chrysanthemum (Chrysanthemum $\times$ morifolium Ramat) cuttings during their rooting phase enhanced plant resistance to an important insect pest, Western flower thrips (Frankliniella occidentalis). For this, we analyzed how several daily UV exposure times affected plant damage by thrips on three different chrysanthemum cultivars. The most effective UV dose and responsive cultivar were further used to determine the UV effects on host plant preference by thrips, leaf metabolome and the induction of jasmonic acid (JA)-associated defenses. Our results showed that while short UV daily exposure times increased chrysanthemum resistance to thrips, longer exposure times had the opposite effect. Furthermore, we showed that UV-mediated induction of chrysanthemum resistance to thrips was genotype dependent and can persist after the end of the of the UV treatment. Yet, this induction was not transferred to the next generation from mother plants to cuttings. Nontargeted metabolomic, enzymatic and hormone analyses further revealed that UV slightly affected the leaf metabolome of chrysanthemum plants, and it enhanced the induction of JA-associated signaling after thrips infestation. Taken together, our results suggest that supplemental UV might modulate both constitutive and inducible chrysanthemum defenses against thrips.
\end{abstract}

Keywords Frankliniella occidentalis $\cdot$ Jasmonic acid $\cdot$ Light $\cdot$ Phenolics $\cdot$ Plant defenses $\cdot$ UV

\section{Key message}

Communicated by Y. Gao.

Special issue on novel management tactics for the Western Flower Thrips.

Electronic supplementary material The online version of this article (https://doi.org/10.1007/s10340-019-01166-w) contains supplementary material, which is available to authorized users.

Rocío Escobar-Bravo rocioebe@hotmail.com

1 Plant Science and Natural Products, Institute of Biology Leiden (IBL), Leiden University, Sylviusweg 72,

2333BE Leiden, The Netherlands

2 Neuchâtel Platform of Analytical Chemistry, University of Neuchâtel, Neuchâtel, Switzerland

3 Present Address: Wageningen University and Research, Business Unit Horticulture, Violierenweg 1,

2665MV Bleiswijk, The Netherlands
- Despite the large number of studies describing the beneficial effects of ultraviolet radiation (UV) on plant resilience to herbivory, no previous work on ornamental species has been reported.

- Here we investigated whether application of supplemental UV radiation increases chrysanthemum resistance to a major insect pest, the Western flower thrips.

- Our data showed that UV can enhance constitutive and inducible chemical defenses against thrips in chrysanthemum, therefore reducing plant damage, but this induction is UV dosage and plant genotype dependent. 


\section{Introduction}

Plants possess an extraordinary capacity to respond and adapt to their changing environment. One of the most important environmental factors affecting plant morphogenesis and chemistry is light. Fluctuations in light influence plant physiology, and plant adaptive responses to biotic stresses, modulating the plant interactions with herbivorous enemies. Both light quantity and quality have been shown to alter plant constitutive and inducible defenses against arthropod herbivores (Escobar-Bravo et al. 2018, 2019a). In particular, variation in ultraviolet radiation $(\lambda 290-400 \mathrm{~nm})$ levels, a relatively small component of the solar light spectrum reaching the terrestrial ecosystems, has been reported to affect plant protection against herbivory (Ballaré 2014). UV radiation is divided into three classes: UV-C, UV-B and UV-A. UV-C radiation is highly energetic $(\lambda \leq 280 \mathrm{~nm})$, and it is strongly absorbed by oxygen and ozone in the stratosphere, being absent in the terrestrial sunlight. UV-B is also absorbed ( $\lambda 290-315 \mathrm{~nm}$ ) in the stratosphere, but a small percentage of the sunlight still contains this radiation. UV-A $(\lambda$ $315-400 \mathrm{~nm}$ ) is not attenuated by atmospheric ozone and, together with UV-B, represents an important environmental light signal regulating many photomorphogenic responses in plants (Bjorn 1994; Robson et al. 2019).

Early research on the biological activity of UV-B radiation suggested detrimental effects on plants. However, recent evidences have demonstrated that ecologically relevant levels are not deleterious (Hectors et al. 2007; Robson et al. 2015). UV-B radiation has emerged as a light cue with potential uses to optimize crop yield and enhance plant protection against insect pests without the use of pesticides (Mazza et al. 2013; Escobar-Bravo et al.2019a). This has led to the conception of UV-B as an 'eustress,' a positive form of stress with beneficial effects on plant health and adaptation to more severe stress conditions (Wargent and Jordan 2013). Indeed, UV-B exposure has been shown to confer cross-tolerance to light stress, drought and high temperatures (Wargent et al. 2011, 2015; Robson et al. 2015; Escobar-Bravo et al. 2017a) and to promote plant resistance to aboveground arthropod herbivores (Foggo et al. 2007; Demkura et al. 2010; Kuhlmann and Müller 2010; Đinh et al. 2013; Zavala et al. 2015; Dillon et al. 2018a, b; Escobar-Bravo et al. 2019a). In addition to UV-B, UV-A has beneficial effects on plants by stimulating seed germination, photosynthesis and growth (Li and Kubota 2009; Mariz-Ponte et al. 2018), although these effects are environment and genotype dependent (Verdaguer et al. 2017).

Among the reported effects of UV-B on plants, this radiation can induce the accumulation of phenolic compounds, which reduces oxidative damage and UV-B penetration to the inner photosynthetic layers (Coffey et al. 2017; Agati and Tattini 2010). These chemical readjustments can affect plant palatability for herbivorous arthropods (reviewed by Escobar-Bravo et al. 2017b). In addition, UV-B can modulate plant inducible defenses. Perception of herbivoreassociated damage triggers plant defense responses, which are mainly regulated by the phytohormones jasmonic acid (JA), salicylic acid (SA) and ethylene (ET) (Erb et al. 2012). Exposure to UV-B can augment the activation of these defense-related hormone signaling pathways upon herbivory leading to a higher production of secondary metabolites and defensive proteins deterring herbivore feeding (Đinh et al. 2013; Dillon et al. 2018a, b).

Besides the potential benefits of UV radiation on plant growth and defenses, many crop species are cultivated in protected environments, i.e., nurseries, glasshouse and greenhouses, built with materials that attenuate or block UV (Jensen and Malter 1995; Vänninen et al. 2010). In these scenarios, artificial manipulation of UV radiation levels could be used to enhance crop protection against pests and diseases at early developmental plant stages (Escobar-Bravo et al. 2019a, b). For instance, application of supplemental UV at an early-stage growth phase is reported to increase plant adaptive responses to higher UV and light intensity levels when plants are transferred to open-field conditions at a later stage (Wargent et al. 2011). This suggests the existence of UV-associated long-term effects on plant performance persisting after the initial light treatment. Yet, whether these effects also translate into a long-lasting enhanced protection against herbivory has not been investigated.

In the present study, we determined the effects of supplemental UV $(\mathrm{A}+\mathrm{B})$ on chrysanthemum [Chrysanthemum $\times$ morifolium (Asteraceae)] resistance to herbivory. Chrysanthemum is one of the economically most important ornamental crops after the rose (da Silva 2004). Its production, however, is threatened by the attack of many insect pests, including the Western flower thrips Frankliniella occidentalis, one of the most serious pests of agricultural and horticultural crops worldwide (Mouden et al. 2017). Chrysanthemum plants are usually propagated by cuttings. Cuttings are planted and rooted in soil for a period of 2 weeks by plant breeding companies before delivered to plant growers for production of flowers. In the Netherlands, one of the main chrysanthemum producers worldwide, this process takes place in greenhouses, where high-pressure sodium (HPS) lamps are the most common supplemental lighting source from fall to spring emitting very low UV levels $(\lambda<400 \mathrm{~nm})$ (Vänninen et al. 2010). Here we tested whether application of supplemental UV $(\mathrm{A}+\mathrm{B})$ to chrysanthemum cuttings during their rooting phase can enhance plant resistance to thrips at early development stages. We determined whether this effect was genotype and UV dosage 
dependent, persisted after the application of the light treatment, and whether it could be transferred to the next generation of cuttings. In addition, we investigated whether UV affected constitutive and JA-associated inducible defenses against thrips, the latter being increasingly important for plant protection against this insect (reviewed by Steenbergen et al. 2018). To do so, we analyzed UV effects on the leaf metabolome before thrips infestation and the induction of a JA-associated defensive protein marker and jasmonate levels before and upon thrips infestation.

\section{Materials and methods}

\section{Plant material and experimental design}

Chrysanthemum [Chrysanthemum $\times$ morifolium Ramat. (Asteraceae)] cuttings (cv. 'Baltica,' 'Pimento' and 'Amadea') were provided by Deliflor Chrysanten (Maasdijk, The Netherlands). In all the experiments, chrysanthemum cuttings were individually planted in plastic pots filled with potting soil (Horticoop, Lentse Potgrond, The Netherlands) containing vermiculite. Thereafter, cuttings were randomly transferred to two climate cabinets (Snyders Scientific B.V.) provided with $\sim 110 \pm 10 \mu \mathrm{mol} \mathrm{m} \mathrm{m}^{-2} \mathrm{~s}^{-1}$ of PAR, a photoperiod of $16 / 8 \mathrm{~h}, 20^{\circ} \mathrm{C}$ and $70 \% \mathrm{RH}$. In one of the cabinets, UV radiation was supplied by two fluorescent lamps (Philips broadband TL 40/12RS) suspended at $65 \mathrm{~cm}$ above the plants, as previously described in Escobar-Bravo et al. (2019a). The lamps were wrapped with white cellulose paper filters ( $40 \mathrm{~g} \mathrm{~m}^{-2}$; Rachow Kunststoff-Folien, Hamburg, Germany) that attenuated the UV intensity and excluded damaging UV-C radiation $(\lambda<280 \mathrm{~nm}$ ) (see UV lamp spectra in Escobar-Bravo et al. 2019a). The UV spectral irradiance [ $\lambda$ 280-400 nm; UV-B: A ratio $(\sim 1: 1.2)$ ] was measured and integrated using a spectroradiometer (Flame-S, Ocean Optics).

\section{UV daily dose experiment}

Cuttings of each of the chrysanthemum varieties ( $n=4-6$ per genotype and treatment) were subjected to the following UV regimes for a period of 14 days: (1) $0 \mathrm{~kJ} \mathrm{~m}^{-2} \mathrm{day}^{-1}$ (control), (2) $0.30 \mathrm{~kJ} \mathrm{~m}^{-2} \mathrm{day}^{-1}$, (3) $0.60 \mathrm{~kJ} \mathrm{~m}^{-2} \mathrm{day}^{-1}$, (4) $1.19 \mathrm{~kJ} \mathrm{~m}^{-2}$ $\mathrm{day}^{-1}$ or (5) $1.79 \mathrm{~kJ} \mathrm{~m}^{-2} \mathrm{day}^{-1}$. This was achieved by exposure to $0,0.5,1,2$ or $3 \mathrm{~h} \mathrm{day}^{-1}$ of UV, respectively. Application of UV started midway through the 16-h light period. At day 15, control and UV-treated plants were transferred to a climate room provided with $\sim 110 \pm 10 \mu \mathrm{mol} \mathrm{m}^{-2} \mathrm{~s}^{-1}$ of PAR, a photoperiod of $16 / 8 \mathrm{~h}, 20^{\circ} \mathrm{C}$ and $70 \% \mathrm{RH}$ and subjected to non-choice whole-plant thrips bioassays. Note that all the insect bioassays described in this study were carried out after the UV treatment terminated, and therefore, thrips performance was not influenced directly by UV but by UVmediated changes in plant physiology.

\section{UV effects on host preference and plant chemical defenses}

In a series of two independent experiments, we selected the most responsive cultivar to UV, 'Pimento,' and the UV daily dose showing the strongest positive effect on plant resistance to thrips (i.e., $1 \mathrm{~h} \mathrm{day}^{-1}$ corresponding to $0.60 \mathrm{~kJ} \mathrm{~m}^{-2}$ day $^{-1}$ ) to determine the effects of UV on: (1) host plant preference by thrips, (2) leaf metabolome and (2) the induction of jasmonic acid-associated defenses after thrips infestation. In all experiments, chrysanthemum cuttings were subjected to control or UV treatments as described above. In the first experiment, plants were sampled for dual-choice leaf disk thrips bioassays $(n=10)$ and metabolomic analysis $(n=5)$ at day 15 after the start of the light treatment. In the second experiment, control and UV-treated plants were subjected to non-choice whole-plant thrips bioassays at day 15 after the start of the light treatments. At $0 \mathrm{~h}$ (before thrips release), $6 \mathrm{~h}, 24 \mathrm{~h}, 3$ days and 7 days after thrips infestation, plants $(n=5)$ were sampled for determination of polyphenol oxidase (PPO) activity, a well-known marker of the activation of JA signaling (Constabel et al. 1995), and the hormones 12-oxo-phytodienoic acid (OPDA), JA and jasmonic acidisoleucine (JA-Ile) levels.

\section{Persistence effects of UV on plant resistance to thrips}

We conducted two separate experiments to test whether UV effect on chrysanthemum resistance to thrips: (1) persists after the end of the UV treatment and (2) can be transferred to the next generation from mother plants to cuttings.

In the first experiment, control and UV chrysanthemum cuttings (cv. 'Pimento') were planted in soil and subjected to control or UV treatments for 2 weeks as described above. Thereafter, plants $(n=10)$ were used for non-choice wholeplant thrips bioassays at days 15 and 21 after the start of the UV treatments, hereafter referred as days 0 and 7 after the UV treatments were finalized.

In the second experiment, chrysanthemum cuttings (cv. 'Pimento') were planted in soil and subsequently subjected to the following UV treatments (see Supplementary Fig. S1 for detailed scheme of the experiment): (1) no UV exposure (control), (2) 2 weeks of UV exposure $\left(0.60 \mathrm{~kJ} \mathrm{~m}^{-2} \mathrm{day}^{-1}\right.$, $\left.1 \mathrm{~h} \mathrm{day}^{-1}\right)$ or (3) 6 weeks of UV exposure $\left(0.60 \mathrm{~kJ} \mathrm{~m}^{-2}\right.$ day $\left.^{-1}, 1 \mathrm{~h} \mathrm{day}^{-1}\right)$. The position of the plants was adjusted every 2 weeks so the distance from the top of the plants to the UV lamps did not vary along the experiment. Cuttings subjected to 2 weeks of UV treatment were transferred to a climate cabinet (without UV), together with 
their corresponding controls (no UV), for four additional weeks. In these climate cabinets, plants were provided with $\sim 110 \pm 10 \mu \mathrm{mol} \mathrm{m} \mathrm{m}^{-2} \mathrm{~s}^{-1}$ of PAR, a photoperiod of $16 / 8 \mathrm{~h}$, $20{ }^{\circ} \mathrm{C}$ and $70 \% \mathrm{RH}$. We used six plastic pots (pot diameter, $23 \mathrm{~cm}$ ) per treatment, each pot containing three cuttings. Three weeks after the start of the experiment, the top of the plants was excised ( $\sim 5 \mathrm{~cm}$ from the top) to stimulate the production of secondary branches. Six weeks after the start of the UV treatments, we obtained one cutting per plant (i.e., 3 cuttings per pot), yielding a total of 18 cuttings per light treatment. Cuttings were planted in individual pots filled with soil and allowed to root for 2 weeks under the same conditions described above for their mother plants but without UV. At day 15 from planting, plants were subjected to non-choice whole-plant thrips bioassays.

\section{Insect rearing}

Western flower thrips (Frankliniella occidentalis) [Pergande] were maintained on chrysanthemum flowers (cultivar 'Euro Sunny') in a climate room at $23{ }^{\circ} \mathrm{C}, 60 \% \mathrm{RH}$ and L12:D12 photoperiod.

\section{Non-choice whole-plant thrips bioassay}

Plants were individually placed into thrips-proof cages as described by Leiss et al. (2009a, b). All cages were randomly placed in a climate room provided with $\sim 110 \pm 10 \mu \mathrm{mol} \mathrm{m}{ }^{-2} \mathrm{~s}^{-1}$ of PAR, a photoperiod of $16 / 8 \mathrm{~h}$, $25{ }^{\circ} \mathrm{C}$ and $70 \% \mathrm{RH}$. Each plant was infested with 10 adult thrips ( 9 females and 1 male). After 7 days, thrips feeding damage (hereafter referred as 'silver damage') was evaluated in all the leaves of the plant and expressed as $\mathrm{mm}^{2}$ of silver damage per plant.

\section{Dual-choice leaf disk thrips bioassay}

A dual-choice assay (Leiss et al. 2009a, b) was used to test thrips preference for chrysanthemum leaves taken from control and UV-treated plants. Leaf disks, each corresponding to an individual plant, with a diameter of $1 \mathrm{~cm}$ were placed on a thin layer of $1 \%$ water agar in a $90-\mathrm{mm}$-diameter Petri dish. For each pairwise, 10 replicates, i.e., petri dishes, were evaluated. Ten starved female $F$. occidentalis adults were shortly anesthetized with $\mathrm{CO}_{2}$ and placed on a small filter paper positioned between the disks. The Petri dishes were sealed with parafilm and placed in a climate room at $25{ }^{\circ} \mathrm{C}$ and 16L:8D light regime. The number of thrips on each leaf disk was recorded at $0.5,1,2,3,4$ and $24 \mathrm{~h}$ after thrips release. At $48 \mathrm{~h}$ after thrips release, silver damage was scored in each leaf disk.

\section{Leaf metabolome analysis}

Nuclear magnetic resonance spectroscopy (NMR) analysis was performed on the third/fourth youngest leaf from the apex in control and UV-treated plants at 14 days after the initial light treatment $(n=5)$. For this, twenty milligrams of freeze-dried plant material was extracted with $1 \mathrm{~mL}$ of $\mathrm{KH}_{2} \mathrm{PO}_{4}$ buffer in $\mathrm{D}_{2} \mathrm{O}(\mathrm{pH}$ 6) containing $0.05 \%$ trimethylsilane propionic acid sodium salt and $\mathrm{CH}_{3} \mathrm{OH}-d_{4}(1: 1)$. Extracts were vortexed, sonicated for $20 \mathrm{~min}$ and centrifuged at 13,000 rpm for $10 \mathrm{~min}$ at room temperature. Three hundred microliters of the supernatant was transferred to NMR tubes for the spectral analysis. ${ }^{1} \mathrm{H}$ NMR spectra were recorded at $25^{\circ} \mathrm{C}$ on a $600-\mathrm{MHz}$ Bruker AV 600 spectrometer equipped with cryoprobe operating at a proton NMR frequency of $600 \mathrm{MHz}$ and analyzed as described in LópezGresa et al. (2012).

\section{Determination of PPO activity}

Polyphenol oxidase (PPO) activity was measured in the third leaf from the apex following the protocol described by Thaler et al. (1999). In short, approx. $150 \mathrm{mg}$ leaf sample was frozen and ground. Enzymes were extracted by homogenizing the plant material in a $2-\mathrm{mL}$ tube with $1.25 \mathrm{~mL}$ icecold $0.1 \mathrm{M} \mathrm{K}$ phosphate buffer $(\mathrm{pH}=8)$ containing $7 \%(\mathrm{w}: \mathrm{v})$ polyvinylpolypyrrolidine and $400 \mu \mathrm{L}$ of $10 \%$ Triton-X-100. The mixture was vortexed and centrifuged at $11.000 \mathrm{rpm}$ at $4{ }^{\circ} \mathrm{C}$ for $10 \mathrm{~min}$. Of the resulting supernatant, $5 \mu \mathrm{L}$ was added to $1 \mathrm{~mL}$ of a chlorogenic acid solution $(2.92 \mathrm{mM}$ in $\mathrm{K}$ phosphate buffer, $\mathrm{pH}=8$ ). The increase in optical density (OD) at $470 \mathrm{~nm}$ was measured by means of a UV-1800 spectrophotometer (Shimadzu Inc., Tokyo, Japan). The change in absorbance was recorded every second for $1 \mathrm{~min}$. The enzyme activity was recorded as $\Delta \mathrm{OD} / \mathrm{min} / \mathrm{g}$ fresh leaf tissue.

\section{Hormone analysis}

The concentrations of OPDA, JA and JA-Ile were determined in the third leaf from the apex following the methodology described in Glauser et al. (2014). For this, the phytohormones were extracted with ethyl acetate spiked with isotopically labeled standards ( $1 \mathrm{ng}$ for $\mathrm{d}_{5}$-JA and ${ }^{13} \mathrm{C}_{6}$-JAIle) and analyzed by ultra-high-performance liquid chromatography tandem mass spectrometry as described in Glauser et al. (2014).

\section{Statistical analysis}

Data were analyzed using the SPSS software package (version 21; SPSS Inc., Chicago, IL, 571 USA). The effects of plant genotype, UV treatment and their interaction on silver 
damage symptoms were analyzed by generalized linear models (GLM) using linear distribution and identity link function, followed by Fisher's least significant difference (LSD) post hoc test. Thrips preference between control and UVtreated plants tested in dual-choice leaf disk thrips bioassays was analyzed by paired $t$ tests. UV treatment, time and their interaction on PPO activity and hormone levels were tested by two-way ANOVA. Data on JA-Ile were Log transformed prior to analysis. Differences in PPO activities and hormone levels between control and UV-treated plants after thrips infestation were analyzed by $t$ tests at each time point. The effect of the UV treatment, the day of thrips infestation after the end of the light treatment and their interaction on silver damage symptoms were analyzed by GLM using linear distribution and identity link function. Differences between control and UV-treated plants at each time point were tested by $t$-tests. The effect of UV treatment, the duration of the light treatment (i.e., 2 or 6 weeks) and their interaction on silver damage symptoms were tested by GLM using linear distribution and identity link function. Patterns of chemical signals detected by NMR in leaf extracts of control and UV-treated plants were first subjected to principal component analysis (PCA). Additionally, supervised partial least squares discriminant analysis (PLS-DA) was used to determine the variation in $\mathrm{X}$ variables (i.e., chemical shifts) modeled by the $\mathrm{Y}$ explanatory variable corresponding to the light treatment. For this, we used the unit variance (UV) scaling method. The cumulative variations in $\mathrm{X}$ and $\mathrm{Y}$ explained by the model were reported as R2X and R2Y, respectively. The resulting model was fitted to the minimum number of latent variables showing the highest value of predicted variation (Q2). The validation of the model was tested by ANOVA of the cross-validated residuals (CVANOVA). The important predictors of the model (i.e., $\mathrm{X}$ variables) were selected based on a variable importance in projection (VIP) score $>1$ (Chong and Jun 2005). Student $t$ tests were used to determine significant variations in the signal intensities of these selected X variables between control and UV-treated plants. Multivariate analyses were performed by using SIMCA-P 13 software (Umetrics, Sweden).

\section{Results}

\section{Effect of different UV daily exposure times on chrysanthemum resistance against thrips}

Variations in the daily UV exposure time significantly affected chrysanthemum resistance to thrips (Fig. 1). UV treatments did not cause any evident sign of damage to plants (Supplementary Fig. S2). The effect of UV on thrips resistance was dependent on the chrysanthemum cultivar

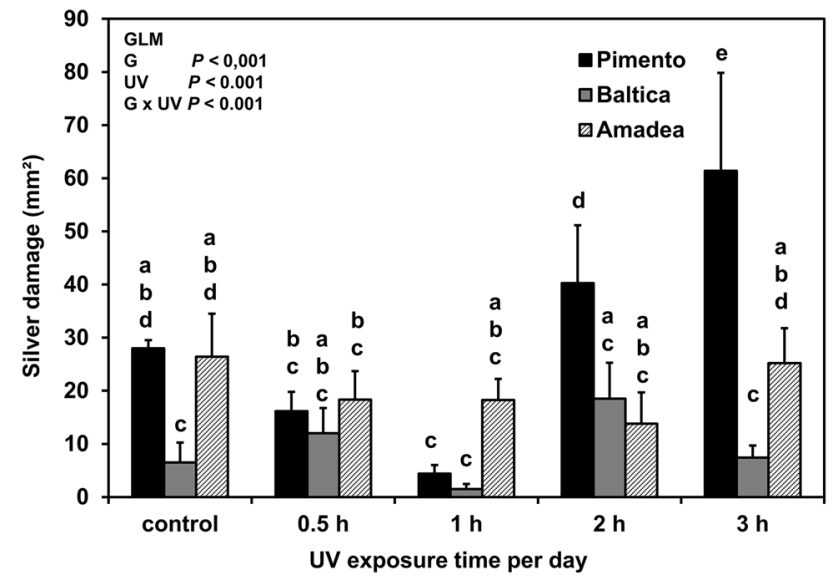

Fig. 1 Effects of several daily UV exposure times on chrysanthemum resistance to thrips. Data represent silver damage symptoms (mean \pm SEM, $n=4-5$ ) evaluated at 7 days after thrips infestation. Chrysanthemum cuttings of the varieties 'Pimento,' 'Amadea' and 'Baltica' were planted in soil and exposed to control $\left(0 \mathrm{~kJ} \mathrm{~m}^{-2} \mathrm{day}^{-1}\right)$, $0.5 \mathrm{~h} \mathrm{day}^{-1}\left(0.30 \mathrm{~kJ} \mathrm{~m}^{-2}\right.$ day $\left.^{-1}\right), 1 \mathrm{~h} \mathrm{day}^{-1}\left(0.60 \mathrm{~kJ} \mathrm{~m}^{-2}\right.$ day $\left.^{-1}\right), 2 \mathrm{~h}^{-1}$ $\left(1.19 \mathrm{~kJ} \mathrm{~m}^{-2} \mathrm{day}^{-1}\right)$ or $3 \mathrm{~h} \mathrm{day}^{-1}\left(1.79 \mathrm{~kJ} \mathrm{~m}^{-2}\right.$ day $\left.^{-1}\right)$ of supplemental UV for 14 consecutive days. At day 15, plants were subjected to nonchoice whole-plant thrips bioassays. Plants were individually infested with 10 adult thrips. Different letters indicate significant differences among groups as determined by GLM followed by Fisher's LSD test $(P \leq 0.05)$. The overall effects of genotype $(\mathrm{G})$, UV and their interaction are indicated

and the daily UV exposure time. A significant reduction in silver damage symptoms was observed in 'Pimento' plants subjected to $1 \mathrm{~h} \mathrm{day}^{-1}$ of supplemental UV. Conversely, UV exposure times of 2 and $3 \mathrm{~h} \mathrm{day}^{-1}$ increased the susceptibility to thrips in 'Pimento' plants, these displaying higher silver damage symptoms than the controls. Although the cultivars 'Baltica' and 'Amadea' also showed a trend of decreasing silver damage symptoms at $1 \mathrm{~h} \mathrm{day}^{-1}$ of supplemental UV, these differences were not significant.

\section{Effect of UV on host plant preference}

We selected the cultivar 'Pimento' and $1 \mathrm{~h} \mathrm{day}^{-1}$ of supplemental UV as the daily dose that showed the strongest positive effect on plant resistance to thrips to test UV effects on host plant preference by thrips using dual-choice leaf disk bioassays. The number of thrips settled on leaf disks taken from control plants was significantly higher than in leaf disks taken from UV-treated plants at $0.5,1$, 2, 3 and $24 \mathrm{~h}$ after thrips release (paired $t$ test, $P \leq 0.05$ ) (Fig. 2a). Furthermore, silver damage symptoms were significantly higher in leaf disks taken from control plants at $48 \mathrm{~h}$ after thrips release (paired $t$ test, $P \leq 0.05$ ) (Fig. 2b). 
A

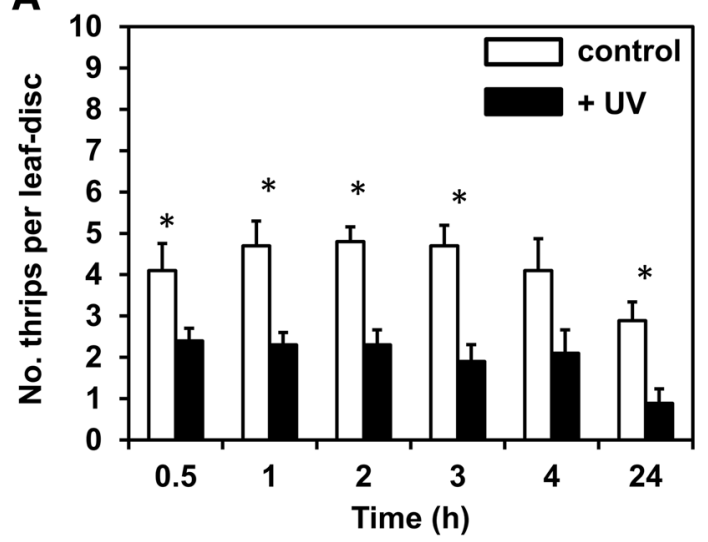

B

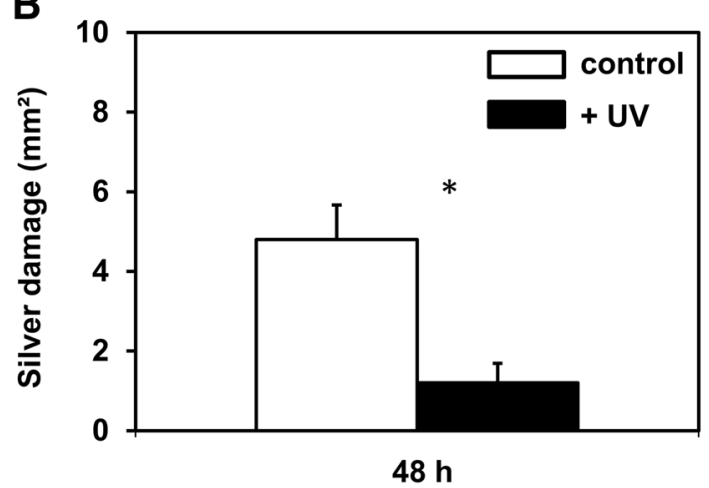

Fig. 2 Effect of supplemental UV on host plant preference by thrips. Chrysanthemum cuttings (cv. 'Pimento') were subjected to control (no UV) or supplemental UV $\left(1 \mathrm{~h} \mathrm{day}^{-1}\right)$ for 14 consecutive days after planting. At day 15, thrips preference was tested by two-choice leaf disk bioassays. a Mean number of thrips $( \pm$ SEM, $n=10)$ settled on leaf disks taken from control or UV-treated plants at different time points after thrips release. b Silver damage symptoms (mean \pm SEM, $n=10$ ) determined at $48 \mathrm{~h}$ after thrips release in leaf disks of control and UV-treated Pimento plants. Data were analyzed by paired twotailed $t$-test. Asterisks denote significant differences at $P \leq 0.05$

\section{Effect of UV on chrysanthemum leaf metabolome}

A total of 241 signals were detected in the leaf extracts of control and UV-treated plants by ${ }^{1} \mathrm{H}$ NMR. PCA of all the detected signals resulted in a model with three principal components explaining $85 \%$ of the variance (model statistics: $\mathrm{R} 2 \mathrm{X}=0.842$ and $\mathrm{Q} 2=0.493$ ) and revealing no significant separation between the metabolomic profiles of plants subjected to control and supplemental UV conditions (Supplementary Fig. S3A, B). To further determine whether UV induced subtle changes in the leaf chemistry, we conducted a supervised multivariate analysis by PLS-DA, which can provide information about the chemical signals whose variation contributes to the separation among classes. This analysis resulted in a model with three latent variables (LVs) explaining $62 \%$ of the total metabolomic variation and $96.5 \%$ of the light treatment response, with a $72.2 \%$
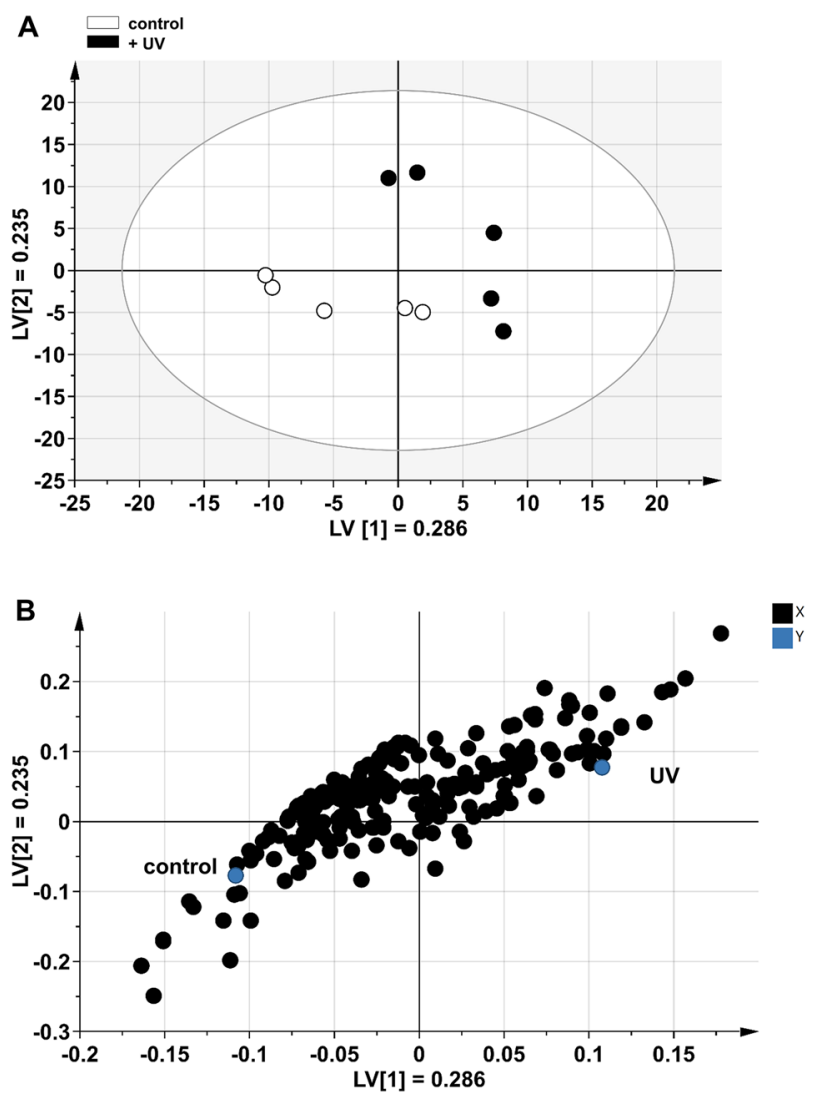

Fig. 3 Metabolomic responses of chrysanthemum (cv. 'Pimento') leaves to control (no UV) or supplemental UV conditions. Supervised partial least square discriminant analysis (PLS-DA) is performed on the obtained ${ }^{1} \mathrm{H}$ NMR spectra of control and UV-treated plants $(n=5)$ at 15 days after the initial light treatment. PLS-DA resulted in a model with three latent variables (LVs) explaining $62 \%$ of the total metabolomic variation and $96.5 \%$ of the UV treatment response with a $72.2 \%$ total model predictability [model statistics: $\mathrm{R} 2 \mathrm{X}=0.63$, $\mathrm{R} 2 \mathrm{Y}=0.965$ and $\mathrm{Q} 2=0.722$ ). Score plot $\mathbf{a}$ and loading plot $\mathbf{b}$ of the first two LV with the explained variance in brackets. In (b), $\mathrm{X}$ depicts the variables (i.e., chemical shifts) modeled by the $\mathrm{Y}$ explanatory variable corresponding to the UV treatment. The ellipse in (a) defines the Hotelling's T2 confidence region (95\%)

total model predictability [model statistics: $\mathrm{R} 2 \mathrm{X}=0.63$, $\mathrm{R} 2 \mathrm{Y}=0.965$ and $\mathrm{Q} 2=0.722$ ). As previously anticipated by the PCA, the resulting PLS-DA model was not statistically significant (CVANOVA, $P=0.46$ ) (Fig. 3a, b). However, among the 69 detected signals with a VIP score $>1$, significant differences in the relative peak intensities between control and UV-treated plants were observed in 10 of them ( $t$ test, $P \leq 0.05$; Fig. 4). Of these, six signals were identified as alanine $(\delta 1.48)$, malic acid $(\delta 2.56,2.84)$, aspartic acid $(\delta 2.80)$ and 3,5-dicaffeoylquinic acid $(\delta 6.48, \delta$ 7.08). UV significantly increased the levels of the amino acid alanine and the phenyl propanoid 3,5-dicaffeoylquinic acid, while it decreased malic and aspartic acid levels in chrysanthemum leaves (Fig. 4). 
Fig. 4 Effect of supplemental UV on leaf metabolome. Relative peak intensity levels $($ mean \pm SEM, $n=5)$ of the detected signals with variable importance in projection (VIP) scores $>1$ and displaying significant differences between control and UV-treated plants determined by student $t$ tests. Asterisks denote significant differences at $P \leq 0.05$. The VIP list was obtained by performing partial least square discriminant analysis. Chemical shifts $(\delta)$ are depicted above each graph

\section{Effect of UV on the induction of jasmonic acid-associated defenses after thrips infestation}

Activation of JA signaling is important for plant resistance to thrips (Li et al. 2002; Escobar-Bravo et al. 2017b). Therefore, we further tested whether UV modulates JA-associated defense responses to thrips infestation in chrysanthemum. For this, we first determined the induction of a JA-responsive marker, PPO activity, in control and UV-treated 'Pimento' plants before and after thrips infestation. PPO activity levels did not differ between control and UV-treated plants before thrips infestation (i.e., 0 h) (Fig. 5a). However, PPO activity levels were significantly higher in UV-treated plants than in their controls at $6 \mathrm{~h}$ after thrips infestation $(t$ test, $P<0.05)$. No significant differences were observed at later time points.

To further investigate the effect of UV on JA signaling, levels of the JA precursor OPDA, JA and JA-Ile were determined in the same time course experiment (Fig. 5). OPDA levels were significantly reduced after thrips infestation in both control and UV-treated plants (Fig. 5b). This response was stronger in UV-treated plants at $24 \mathrm{~h}$. JA levels also declined in control and UV-treated plants after thrips control

+ UV
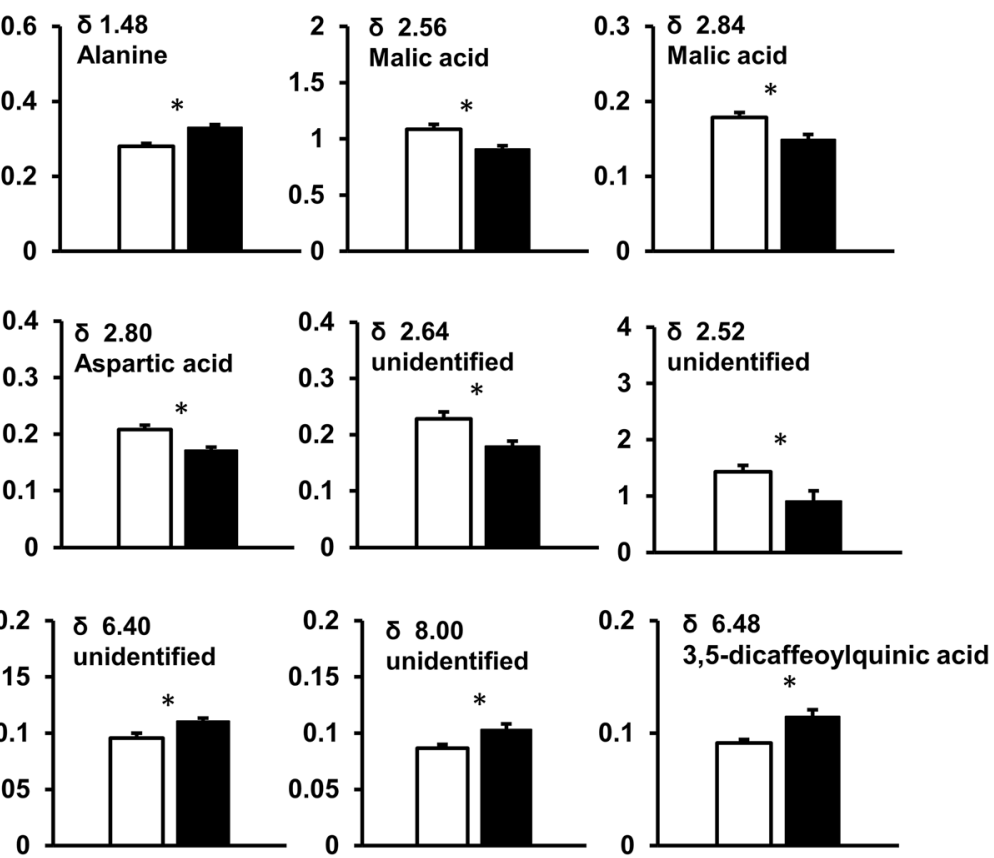

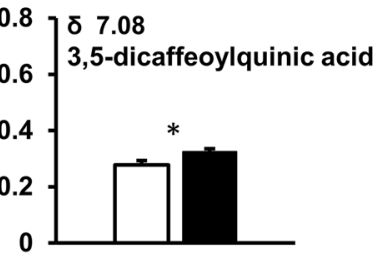

infestation, being significantly lower in UV-treated plants when compared with their controls at $24 \mathrm{~h}$ (Fig. 5c). Conversely, JA-Ile levels were significantly induced in control and UV-treated plants at 6, 24, 72 and $168 \mathrm{~h}$ after thrips infestation (Fig. 5d). At 7 days after thrips infestation $(168 \mathrm{~h})$, however, JA-Ile levels were significantly higher in UV-treated than in control plants.

\section{Persistence of the UV effect on chrysanthemum resistance to thrips}

The effects of UV on chrysanthemum resistance persisted after the end of the UV treatment, but it was not transferred to the next generation from mother plants to cuttings (Fig. 6a, b). Silver damage symptoms were significantly lower in UV-treated plants compared to their controls when plants were infested at 0 or 7 days after the end of the light treatments (Fig. 6a). However, cuttings obtained from chrysanthemum mother plants subjected to two or six consecutive weeks of $\mathrm{UV}$ treatment (i.e., $1 \mathrm{~h} \mathrm{day}^{-1}$ ) did not displayed enhanced resistance to thrips when compared to the controls (Fig. 6b). 


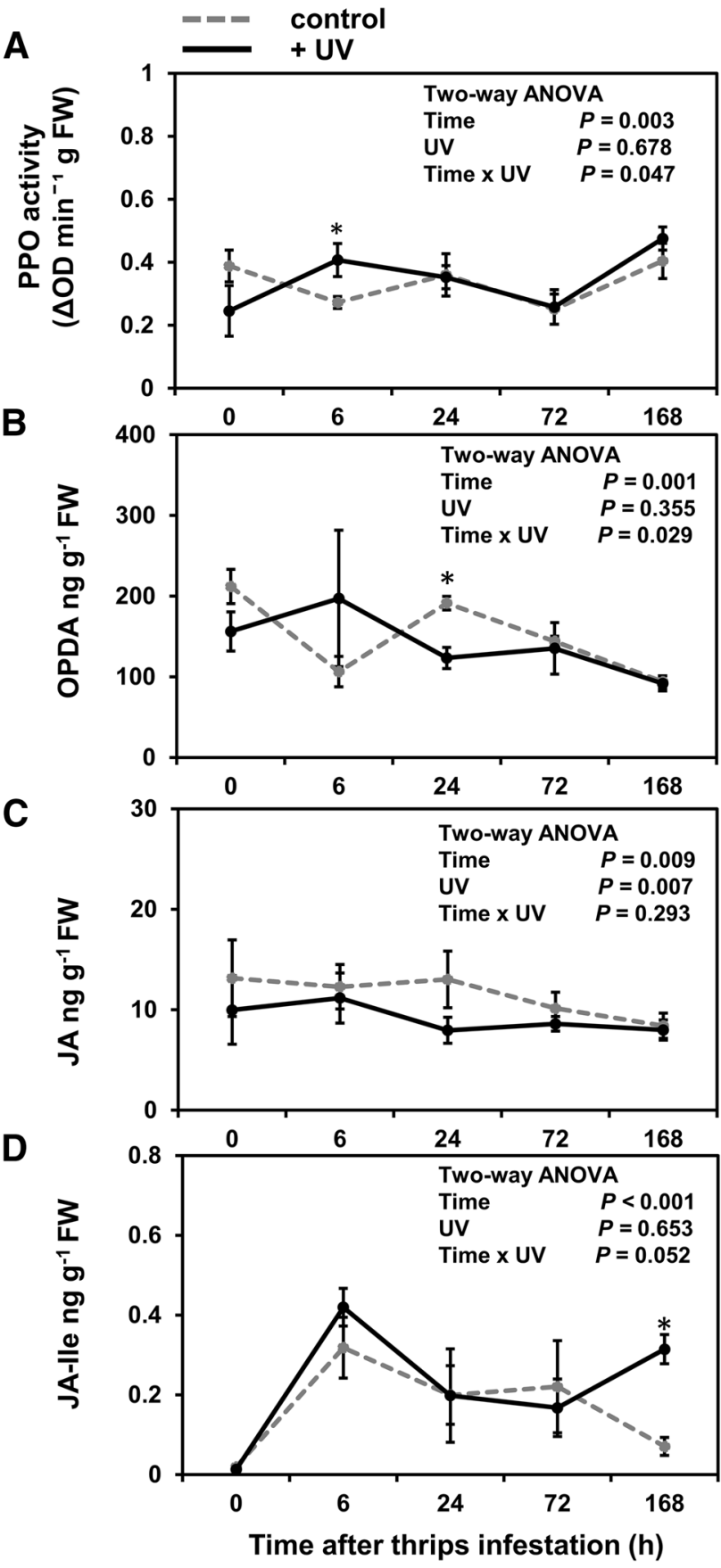

Fig. 5 Effect of supplemental UV on thrips-mediated induction of jasmonic acid-mediated signaling. a Polyphenol oxidase (PPO) activity (mean \pm SEM, $n=5$ ), b 12-oxo-phytodienoic acid (OPDA), c jasmonic acid (JA) and $\mathbf{d}$ jasmonic acid-isoleucine (JA-Ile) levels (mean \pm SEM, $n=3-5$ ) determined in control and UV-treated chrysanthemum cuttings (cv. 'Pimento') at 0, 6, 24, 72 and $168 \mathrm{~h}$ after thrips infestation. Cuttings were subjected to control (no UV) or supplemental UV $\left(1 \mathrm{~h} \mathrm{day}^{-1}\right)$ for 14 consecutive days after planting. At day 15 , plants were individually infested with 10 thrips in non-choice whole-plant bioassays and sampled for PPO and hormonal analysis. The overall effects of time of sampling, UV and their interaction tested by two-way ANOVA are indicated. Asterisks denote significant differences at $P \leq 0.05$ tested by unpaired $t$ test
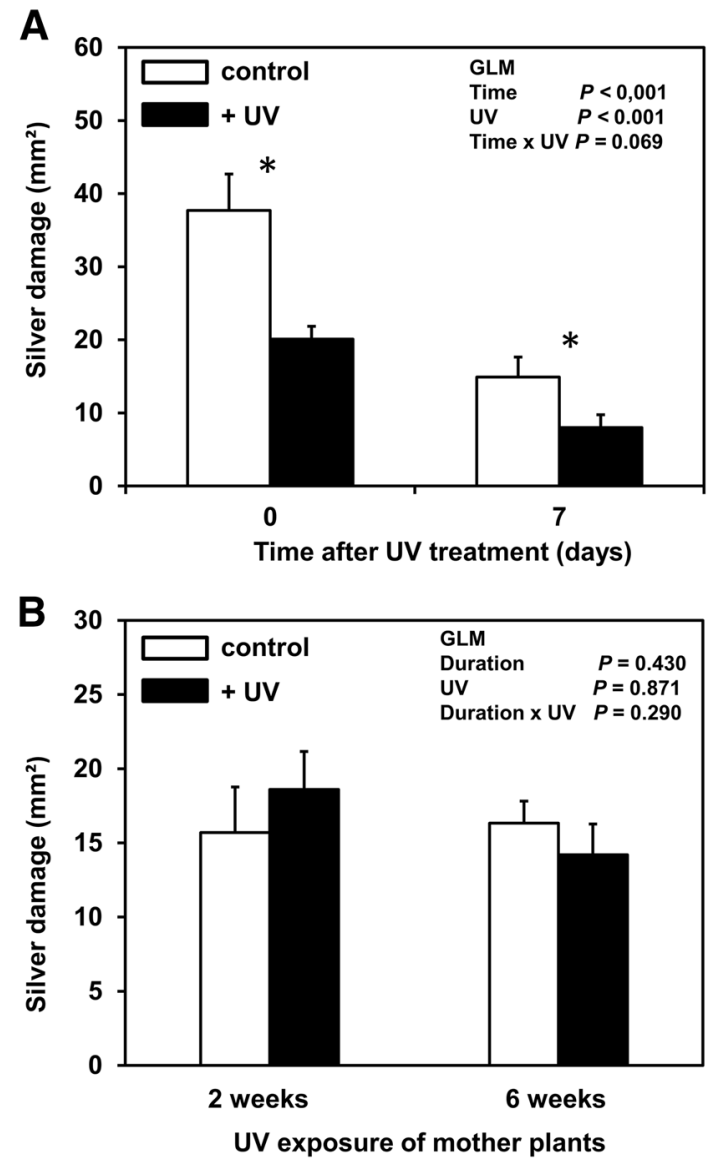

Fig. 6 Persistency of UV effects on chrysanthemum resistance to thrips. a Silver damage symptoms (mean \pm SEM, $n=10$ ) determined in control and UV-treated chrysanthemum plants (cv. 'Pimento') at 7 days after thrips infestation. Cuttings were subjected to control (no $\mathrm{UV})$ or supplemental UV ( $\left.1 \mathrm{~h} \mathrm{day}^{-1}\right)$ for 14 consecutive days after planting. At days 15 and 21 (referred as days 0 and 7) after the initial treatment plants were individually infested with thrips (10 adults per plant). The overall effects of time of infestation, UV treatment and their interaction tested by generalized linear models (GLM) are indicated in the graph. Asterisks denote significant differences at $P \leq 0.05$ tested by unpaired $t$ test. b Silver damage symptoms (mean \pm SEM, $n=18$ ) determined in plants propagated from mother plants subjected to control or supplemental UV radiation (cv. 'Pimento'). Mother plants were grown from cuttings (cv. 'Pimento') and subjected to control or supplemental UV $\left(1 \mathrm{~h} \mathrm{day}{ }^{-1}\right)$ for a period of two or six consecutive weeks. Thereafter, cuttings obtained from these mother plants were planted and grown in soil for 2 weeks without UV. At day 15 , plants were individually infested with 10 adult thrips, and silver damage symptoms evaluated at 7 days after infestation. The overall effects of the UV treatment, duration of the light treatment (i.e., 2 or 6 weeks) and their interaction were tested by generalized linear models (GLM). Results of the statistical analysis are indicated in the graph

\section{Discussion}

In the present study, we demonstrated that application of supplemental UV radiation enhances chrysanthemum resistance to thrips. We showed that this effect was genotype and 
UV dosage dependent and persisted after the light treatment finalized. Furthermore, our analyses revealed that supplemental UV induced subtle changes on the chemical profile of chrysanthemum leaves, and it might prime JA-associated defenses against thrips.

First, our results showed that application of supplemental UV increased thrips resistance in the cultivar 'Pimento,' with similar but not significant trends in the other cultivars 'Amadea' and 'Baltica' (Fig. 1). In addition, it enhanced the antixenotic properties of 'Pimento' plants as shown in the preference bioassay (Fig. 2a, b). F. occidentalis adults can live up to 30 days and lay 2-10 eggs per day that hatch after 2-4 days (Rotenberg et al. 2015). We measured silver damage at 7 days after thrips infestation. At this time point, plant damage might result from adult WFT feeding, but also from their developing larvae. Thus, reduction in damage levels might be explained by a reduction in the survival of adults and larvae, but also by a reduced oviposition rate. Notably, the preference bioassays showed that adult thrips settled and fed less in leaf disks taken from UV-treated plants, which might have negatively influenced the oviposition rate. This is an aspect that needs further research.

Photomorphogenic and stress-associated responses to UV can vary among plant genotypes (Hidema et al. 1997; Correia et al. 1999; Cooley et al. 2001; Kalbina and Strid 2006; Mariz-Ponte et al. 2018), and this variation most probably explains the different responses observed in our study. For instance, UV-B elicited changes in foliar chemistry that were markedly different in two populations of white clover (Trifolium repens $\mathrm{L}$.), which also coincided with variations in susceptibility to a generalist herbivore (Lindroth et al. 2000). In another example, Zavala et al. (2015) reported differences in the UV-mediated induction of isoflavonoids in soybean pods among four cultivars. Furthermore, these differences were associated with plant susceptibility to stink bug herbivory. Interestingly, our data also showed that while low UV doses enhanced thrips resistance in the cultivar 'Pimento,' high UV doses had the opposite effect (Fig. 1). The fact that this UV dose-dependent effect was only evident in this genotype might be explained by a higher sensitivity to UV in comparison with the other chrysanthemum cultivars. UV sensitivity can be correlated with differences in anatomical and biochemical leaf traits, including thickness, trichomes and composition and concentration of UV-absorbing compounds (Murali et al. 1988; Yan et al. 2012; Escobar-Bravo et al. 2019a). Further analysis to determine whether these parameters can determine differences in chrysanthemum responses to UV are thus needed. In addition, we hypothesize that the enhanced thrips susceptibility triggered by longer UV exposure times (i.e., 2 and $3 \mathrm{~h} \mathrm{day}^{-1}$ ) can be explained by an increase in the oxidative stress and the subsequent activation of SA signaling in the plant. Upon irradiation with high doses of UV, accumulation of SA and/or expression of pathogenesis-related genes has been previously described in the literature (Surplus et al. 1998; Mackerness et al. 1999; Fujibe et al. 2000; Bandurska and Cieślak 2013; Kovács et al. 2014). In this sense, activation of SA signaling has been reported to increase plant susceptibility to thrips, probably due to its antagonistic effect on JA-induced defenses (León-Reyes et al. 2009; Abe et al. 2012). Yet, whether the activation of SA defenses under long UV exposure times is responsible for the increased chrysanthemum susceptibility to thrips described here is an aspect that needs further analysis.

To determine how UV enhances chrysanthemum defenses against thrips, we analyzed the metabolomic profiles of UVtreated 'Pimento' leaves. Our data showed that application of low UV levels (i.e., $1 \mathrm{~h} \mathrm{day}^{-1}$ ) barely affected the leaf chemical profiles of chrysanthemum plants at 15 days after the start of the UV treatment (Supplementary Fig. S3A, B). Still, we detected significant variations in the relative peak intensities of several signals of the NMR spectra (Fig. 4). Interestingly, a significant induction of the phenyl propanoid 3,5-dicaffeoylquinic acid levels was observed in UV-treated plants. UV-B can induce the production of phenolic compounds in many plant species (Wargent et al. 2015; Hectors et al. 2014; Barnes et al. 2016). In chrysanthemum, Yang et al. (2018) reported significant changes in the leaf content of total and individual flavonoids and phenylpropanoids in plants exposed to $12 \mathrm{~h}$ of UV-B, but not after 3 or $6 \mathrm{~h}$ of exposure. This suggests a UV dose-dependent effect on leaf production of phenolics. Indeed, we have recently reported that exposure to low levels of supplemental UV $(\mathrm{A}+\mathrm{B})$ (i.e., 30 min day ${ }^{-1}, 0.34 \mathrm{~kJ} \mathrm{~m}^{-2}$ day $^{-1}$ ) did not significantly alter the production of the main phenolic components of tomato leaves, i.e., rutin and chlorogenic acid (EscobarBravo et al. 2019a). Experimental conditions such as photosynthetically active radiation (PAR) levels and temperature might modulate UV-associated plant responses (Cen and Bornman 1990; Götz et al. 2010). For instance, in temperate regions characterized by low daily light integrals and moderate temperatures, Coffey et al. (2017) did not detect a significant effect of UV-B on the production of phenolics in Arabidopsis plants growing outdoors. It is therefore feasible that under our experimental conditions, UV radiation also failed to induce a strong metabolic response in chrysanthemum. Notably, enhanced levels of the phenylpropanoids chlorogenic and feruloyl quinic acids have been previously associated with thrips resistance in chrysanthemum (Leiss et al. 2019). Their induction might therefore explain the differences in thrips damage, but also in the thrips preference observed in our study. Indeed, Leiss et al. (2019) showed that in choice assays thrips significantly preferred artificial diet without chlorogenic acid over that containing this phenolic acid even at low concentrations. It would be interesting to determine whether other phenylpropanoids, 
such as 3,5-dicaffeoylquinic acid, also affect herbivore resistance. How variations in alanine, aspartic acid and malic acid might have contributed to plant defenses against thrips is not clear. Yet, changes in amino acid levels in response to biotic stresses have been amply reported in the literature (Less and Galili 2008). This has been explained by their important role as precursors for the biosynthesis of defensive metabolites against herbivorous enemies (Zhou et al. 2015). In this sense, it should be noticed that reduction in aspartic acid levels might be associated with an increased biosynthesis of other amino acids and proteins (Azevedo et al. 2006). Notably, thrips infestation has been reported to induce the expression of defense-associated proteinase inhibitor proteins in tomato (Escobar-Bravo et al. 2017a) and soybean (Dillon et al. 2018a, b). Taken together, these results suggest that UV-mediated induction of chrysanthemum defenses against thrips might be only partially explained by small changes in the leaf secondary and primary metabolites.

Our results further showed that UV-treated chrysanthemum plants experienced a stronger induction of the JA signaling after thrips infestation. Thrips infestation induced the accumulation of the bioactive form of JA and JA-Ile, in control and UV-treated plants (Fig. 5d), which agrees with previous results reported in Arabidopsis (Abe et al. 2008) and sweet pepper (Sarde et al. 2018). This induction was accompanied by a general decrease in OPDA and JA levels after thrips infestation, which might be explained by their conversion into JA-Ile (Wasternack and Song 2016). Interestingly, UV-treated plants displayed significantly higher JA-Ile levels at 7 days after thrips infestation when compared to the controls (Fig. 5d). Furthermore, thrips infestation enhanced PPO activity levels in UV-treated plants but not in the controls. PPO is a wellknown marker of the activation of JA-associated defenses (Thaler et al. 1999). Its induction, however, can depend on the amount of herbivore-associated damage (Stout et al. 1994). We thus hypothesize that the silver damage levels caused by thrips were insufficient to activate these chemical defenses, but they might have been augmented in UV-treated plants. UV-B radiation is reported to increase the accumulation of bioactive jasmonates (JAs) and the plant sensitivity to JAs (Ballaré et al. 2011). Either solar or supplemental UV-B has been described to enhance the expression of JA-associated defense responses upon herbivory or wounding (e.g., Demkura et al. 2010; Đinh et al. 2013; Qi et al. 2018). This resulted in a stronger induction of defense-related proteins and secondary metabolites and, consequently, plant resistance to herbivory. For instance, (Đinh et al. 2013) and Demkura et el. (2010) showed that UV-B exposure increased the expression levels of the defense-associated gene NaTPI in Nicotiana attenuata plants at 12 and $24 \mathrm{~h}$ after simulated herbivory. Thrips are susceptible to the activation of JA defenses ( $\mathrm{Li}$ et al. 2002; Abe et al. 2012; Escobar-Bravo et al. 2017a). A stronger induction of this signaling pathway might therefore explain the reduction in silver damage symptoms observed in UV-treated chrysanthemum plants. Hence, our results further support UV as a 'priming' agent for a more robust induction of anti-herbivore defenses. However, more analyses are needed to determine which components of the JA-dependent metabolism are responsible for the enhanced chrysanthemum defenses against thrips.

Additional bioassays revealed that the positive effects of UV on chrysanthemum resistance to thrips are still evident at 7 days from the end of the UV treatment, suggesting a potential long-lasting protection (Fig. 6a). To the best of our knowledge, no other study has specifically tested the duration of the UV effects on plant resistance to herbivory. Probably, changes in plant chemistry and/or the 'priming' state, both induced by UV radiation, persisted after ceasing the light signal. In the latter case, defense priming can be induced by chemical cues such as phytohormones or volatile organic compounds, pathogens, arthropod herbivores, beneficial microorganisms or abiotic stresses (Conrath et al. 2015; Martinez-Medina et al. 2016; Mauch-Mani et al. 2017). The time between the initial 'priming' stimuli and the challenge that triggers plant defense responses can range from hours to days (Pieterse et al. 1996; Walters et al. 2008), which supports the hypothesis of a long-lasting effect of UV on chrysanthemum defenses. However, our data also showed that UV effects on chrysanthemum resistance to thrips were not transferred to the next generation from mother plants to cuttings (Fig. 6b). This implies that the effects of UV on chrysanthemum physiology were not fixed and they dilute with time.

In recent years, several studies have reported the use of supplemental UV to alter the chemistry of medicinal chrysanthemum (Chrysanthemum morifolium Ramat) flowers, for which the main active components are flavonoids and chlorogenic acid (Yao et al. 2014; Ma et al. 2016). Here we showed that supplemental UV radiation can be used to enhance chrysanthemum defenses against an important insect pest during the vegetative stage as well. Future experiments should further address whether application of UV can also alter the chemical defenses of flowers, which are heavily attacked by thrips and enhance their protection against this herbivorous pest. Our results have important implications for floriculture, as it might restrict thrips infestations of chrysanthemum plants at early development stages. Moreover, our study demonstrates the existence of phenotypic variation in UV-mediated induced defenses against herbivory among chrysanthemum cultivars, which could be potentially exploited in breeding programs for enhanced pest control. 


\section{Author contributions}

REB, PK and KL designed the experiments. REB, CN, SN and MJRL performed the experiments. HYK and GC performed the NMR analysis. REB and GG performed the hormone analyses. REB wrote the manuscript with the input of all the co-authors.

Acknowledgements This work was supported by the STW Perspective program 'Green Defense against Pests' (GAP) (Ref. 13553). The work of Gang Chen is funded by the China Scholarship Council (CSC) of the Ministry of Education. We thank the companies involved in the GAP project: Rijk Zwaan, Dümmen Orange, Deliflor, Dekker Chrysanten and Incotec for financial support.

\section{Compliance with ethical standards}

Conflict of interest The authors declare that they have no conflict of interest.

Ethical approval This article does not contain any studies with human participants or animals performed by any of the authors.

Open Access This article is distributed under the terms of the Creative Commons Attribution 4.0 International License (http://creativeco mmons.org/licenses/by/4.0/), which permits unrestricted use, distribution, and reproduction in any medium, provided you give appropriate credit to the original author(s) and the source, provide a link to the Creative Commons license, and indicate if changes were made.

\section{References}

Abe H, Ohnishi J, Narusaka M, Seo S, Narusaka Y, Tsuda S, Kobayashi M (2008) Function of jasmonate in response and tolerance of Arabidopsis to thrip feeding. Plant Cell Physiol 49:68-80

Abe H, Tomitaka Y, Shimoda T, Seo S, Sakurai T, Kugimiya S, Tsuda S, Kobayashi M (2012) Antagonistic plant defense system regulated by phytohormones assists interactions among vector insect, thrips and a tospovirus. Plant Cell Physiol 53:204-212

Agati G, Tattini M (2010) Multiple functional roles of flavonoids in photoprotection. New Phytol 186:786-793

Azevedo RAD, Lancien M, Lea PJ (2006) The aspartic acid metabolic pathway, an exciting and essential pathway in plants. Amino Acids 30:143-162

Ballaré CL (2014) Light regulation of plant defense. Annu Rev Plant Biol 65:335-363

Ballaré CL, Caldwell MM, Flint SD, Robinson SA, Bornman JF (2011) Effects of solar ultraviolet radiation on terrestrial ecosystems. Patterns, mechanisms, and interactions with climate change. Photochem Photobiol Sci 10:226-241

Bandurska H, Cieślak M (2013) The interactive effect of water deficit and UV-B radiation on salicylic acid accumulation in barley roots and leaves. Environ Exper Bot 94:9-18

Barnes PW, Tobler MA, Keefover-Ring K, Flint SD, Barkley AE, Ryel RJ, Lindroth RL (2016) Rapid modulation of ultraviolet shielding in plants is influenced by solar ultraviolet radiation and linked to alterations in flavonoids. Plant Cell Environ $39: 222-230$
Bjorn LO (1994) Introduction. In: Kendrick RE, Kronenberg GHM (eds) Photomorphogenesis in plants, 2nd edn. Kluwer Academic Publishers, Boston, pp 3-25

Cen YP, Bornman JF (1990) The response of bean plants to UV-B radiation under different irradiances of background visible light. J Exp Bot 41:1489-1495

Chong IG, Jun CH (2005) Performance of some variable selection methods when multicollinearity is present. Chemometr Intell Lab Syst 78:103-112

Coffey A, Prinsen E, Jansen MAK, Conway J (2017) The UVB photoreceptor UVR8 mediates accumulation of UV-absorbing pigments, but not changes in plant morphology, under outdoor conditions. Plant Cell Environ 40:2250-2260

Conrath U, Beckers GJ, Langenbach CJ, Jaskiewicz MR (2015) Priming for enhanced defense. Annu Rev Phytopathol 53:97-119

Constabel CP, Bergey DR, Ryan CA (1995) Systemin activates synthesis of wound-inducible tomato leaf polyphenol oxidase via the octadecanoid defense signaling pathway. PNAS 92:407-411

Cooley NM, Higgins JT, Holmes MG, Attridge TH (2001) Ecotypic differences in responses of Arabidopsis thaliana L. to elevated polychromatic UV-A and UV-B + A radiation in the natural environment: a positive correlation between UV-B + A inhibition and growth rate. J Photochem Photobiol B B 60:143-150

Correia CM, Areal ELV, Torres-Pereira MS, Torres-Pereira JMG (1999) Intraspecific variation in sensitivity to ultraviolet-B radiation in maize grown under field conditions: II. Physiological and biochemical aspects. Field Crops Res 62:97-105

da Silva JAT (2004) Ornamental chrysanthemums: improvement by biotechnology. Plant Cell Tissue Organ Cult 79:1-18

Demkura PV, Abdala G, Baldwin IT, Ballaré CL (2010) Jasmonatedependent and-independent pathways mediate specific effects of solar ultraviolet $\mathrm{B}$ radiation on leaf phenolics and antiherbivore defense. Plant Physiol 152:1084-1095

Dillon FM, Chludil HD, Reichelt M, Mithöfer A, Zavala JA (2018a) Field-grown soybean induces jasmonates and defensive compounds in response to thrips feeding and solar UV-B radiation. Environ Exp Bot 156:1-7

Dillon FM, Tejedor MD, Ilina N, Chludil HD, Mithöfer A, Pagano EA, Zavala JA (2018b) Solar UV-B radiation and ethylene play a key role in modulating effective defenses against Anticarsia gemmatalis larvae in field-grown soybean. Plant Cell Environ 41:383-394

Đinh ST, Galis I, Baldwin IT (2013) UVB radiation and 17-hydroxygeranyllinalool diterpene glycosides provide durable resistance against mirid (Tupiocoris notatus) attack in field-grown Nicotiana attenuata plants. Plant Cell Environ 36:590-606

Erb M, Meldau S, Howe GA (2012) Role of phytohormones in insectspecific plant reactions. Trends Plant Sci 17:250-259

Escobar-Bravo R, Klinkhamer P, Leiss KA (2017a) Induction of jasmonic acid-associated defenses by thrips alters host suitability for conspecifics and correlates with increased trichome densities in tomato. Plant Cell Physiol 58:622-634

Escobar-Bravo R, Klinkhamer PG, Leiss KA (2017b) Interactive effects of UV-B light with abiotic factors on plant growth and chemistry, and their consequences for defense against arthropod herbivores. Front Plant Sci 8:278

Escobar-Bravo R, Ruijgrok J, Kim HK, Grosser K, van Dam NM, Klinkhamer PGL, Leiss KA (2018) Light intensity-mediated induction of Trichome-associated allelochemicals increases resistance against thrips in tomato. Plant Cell Physiol 59:2462-2475

Escobar-Bravo R, Chen G, Kim HK, Grosser K, Leiss KA, Klinkhamer PGL (2019a) Ultraviolet radiation exposure time and intensity modulate tomato resistance to herbivory through activation of jasmonic acid signaling. J Exp Bot 70:315-327

Escobar-Bravo R, Chen G, Grosser K, Van Dam, NM, Leiss KA, Klinkhamer PG (2019b) Ultraviolet radiation enhances salicylic acid-mediated defense signaling and resistance to Pseudomonas 
syringae DC3000 in a jasmonic acid-deficient tomato mutant. Plant Signal Behav 14(4):e1581560

Foggo A, Higgins S, Wargent JJ, Coleman RA (2007) Tri-trophic consequences of UV-B exposure: plants, herbivores and parasitoids. Oecologia 154:505-512

Fujibe T, Watanabe K, Nakajima N, Ohashi Y, Mitsuhara I, Yamamoto KT, Takeuchi Y (2000) Accumulation of pathogenesisrelated proteins in tobacco leaves irradiated with UV-B. J Plant Res 113:387-394

Glauser G, Vallat A, Balmer D (2014) Hormone profiling. Methods. Mol Biol 1062:597-608

Götz M, Albert A, Stich S, Heller W, Scherb H, Krins A, Langebartels C, Seidlitz HK, Ernst D (2010) PAR modulation of the UVdependent levels of flavonoid metabolites in Arabidopsis thaliana (L.) Heynh. leaf rosettes: cumulative effects after a whole vegetative growth period. Protoplasma 243:95-103

Hectors K, Prinsen E, De Coen W, Jansen MA, Guisez Y (2007) Arabidopsis thaliana plants acclimated to low dose rates of ultraviolet B radiation show specific changes in morphology and gene expression in the absence of stress symptoms. New Phytol 175:255-270

Hectors K, Van Oevelen S, Geuns J, Guisez Y, Jansen MA, Prinsen E (2014) Dynamic changes in plant secondary metabolites during UV acclimation in Arabidopsis thaliana. Physiol Plant 152:219-230

Hidema J, Kumagai T, Sutherland JC, Sutherland BM (1997) Ultraviolet $\mathrm{B}$-sensitive rice cultivar deficient in cyclobutyl pyrimidine dimer repair. Plant Physiol 113:39-44

Jensen MH, Malter AJ (1995) Protected agriculture: a global review, vol 253. World Bank Publications, Washington DC

Kalbina I, Strid Å (2006) Supplementary ultraviolet-B irradiation reveals differences in stress responses between Arabidopsis thaliana ecotypes. Plant Cell Environ 29:754-763

Kovács V, Gondor OK, Szalai G, Majláth I, Janda T, Pál M (2014) UV-B radiation modifies the acclimation processes to drought or cadmium in wheat. Environ Exp Bot 100:122-131

Kuhlmann F, Müller C (2010) UV-B impact on aphid performance mediated by plant quality and plant changes induced by aphids. Plant Biol 12:676-684

Leiss KA, Choi YH, Abdel-Farid IB, Verpoorte R, Klinkhamer PG (2009a) NMR metabolomics of thrips (Frankliniella occidentalis) resistance in Senecio hybrids. J Chem Ecol 35:219-229

Leiss KA, Maltese F, Choi YH, Verpoorte R, Klinkhamer PG (2009b) Identification of chlorogenic acid as a resistance factor for thrips in chrysanthemum. Plant Physiol 150:1567-1575

León-Reyes A, Spoel SH, De Lange ES, Abe H, Kobayashi M, Tsuda S, Millenaar FF, Welschen RA, Ritsema T, Pieterse CM (2009) Ethylene modulates the role of NONEXPRESSOR OF PATHOGENESIS-RELATED GENES1 in cross talk between salicylate and jasmonate signaling. Plant Physiol 149:1797-1809

Less H, Galili G (2008) Principal transcriptional programs regulating plant amino acid metabolism in response to abiotic stresses. Plant Physiol 147:316-330

Li Q, Kubota C (2009) Effects of supplemental light quality on growth and phytochemicals of baby leaf lettuce. J Exp Bot 67:59-64

Li C, Williams MM, Loh YT, Lee GI, Howe GA (2002) Resistance of cultivated tomato to cell content-feeding herbivores is regulated by the octadecanoid-signaling pathway. Plant Physiol 130:494-503

Lindroth RL, Hofman RW, Campbell BD, McNabb WC, Hunt DY (2000) Population differences in Trifolium repens L. response to ultraviolet-B radiation: foliar chemistry and consequences for two lepidopteran herbivores. Oecologia 122:20-28

López-Gresa MP, Lisón P, Kim HK, Choi YH, Verpoorte R, Rodrigo I, Conejero V, Bellés JM (2012) Metabolic fingerprinting of tomato mosaic virus infected Solanum lycopersicum. J Plant Physiol 169:1586-1596

Ma CH, Chu JZ, Shi XF, Liu CQ, Yao XQ (2016) Effects of enhanced UV-B radiation on the nutritional and active ingredient contents during the floral development of medicinal chrysanthemum. J Photochem Photobiol B Biol 158:228-234

Mackerness SAH, Surplus S, Blake P, John C, Buchanan-Wollaston V, Jordan B, Thomas B (1999) Ultraviolet-B-induced stress and changes in gene expression in Arabidopsis thaliana: role of signaling pathways controlled by jasmonic acid, ethylene and reactive oxygen species. Plant Cell Environ 22:1413-1423

Mariz-Ponte N, Mendes RJ, Sario S, Ferreira de Oliveira JMP, Melo P, Santos C (2018) Tomato plants use non-enzymatic antioxidant pathways to cope with moderate UV-A/B irradiation: a contribution to the use of UV-A/B in horticulture. J Plant Physiol 221:32-42

Martinez-Medina A, Flors V, Heil M, Mauch-Mani B, Pieterse CMJ, Pozo MJ, Ton J, van Dam NM, Conrath U (2016) Recognizing plant defense priming. Trends Plant Sci 21:818-822

Mauch-Mani B, Baccelli I, Luna E, Flors V (2017) Defense priming: an adaptive part of induced resistance. Annu Rev Plant Biol 68:485-512

Mazza CA, Giménez PI, Kantolic AG, Ballaré CL (2013) Beneficial effects of solar UV-B radiation on soybean yield mediated by reduced insect herbivory under field conditions. Physiol Plant 147:307-315

Mouden S, Sarmiento KF, Klinkhamer PG, Leiss KA (2017) Integrated pest management in western flower thrips: past, present and future. Pest Manag Sci 73:813-822

Murali NS, Teramura AH, Randall SK (1988) Response differences between two soybean cultivars with contrasting UV-B radiation sensitivities. Photochem Photobiol 48:653-657

Pieterse CM, Van Wees SC, Hoffland E, Van Pelt JA, Van Loon LC (1996) Systemic resistance in Arabidopsis induced by biocontrol bacteria is independent of salicylic acid accumulation and pathogenesis-related gene expression. Plant Cell 8:1225-1237

Qi J, Zhang M, Lu C, Hettenhausen C, Tan Q, Cao G, Zhu X, Wu G, Wu J (2018) Ultraviolet-B enhances the resistance of multiple plant species to lepidopteran insect herbivory through the jasmonic acid pathway. Sci Rep 8:277

Robson T, Klem K, Urban O, Jansen MA (2015) Re-interpreting plant morphological responses to UV-B radiation. Plant Cell Environ 38:856-866

Robson TM, Aphalo PJ, Banas AK, Barnes PW, Brelsford CC, Jenkins GI, Kotilainen T, Labuz TJ, Martínez-Abaigar J, Morales LO, Neugart S, Pieristè M, Rai N, Vandenbussche F, Jansen M (2019) A perspective on ecologically relevant plant-UV research and its practical application. Photochem Photobiol Sci 18(5):970-988

Rotenberg D, Jacobso AL, Schneweis DJ, Whitfield AE (2015) Thrips transmission of tospoviruses. Curr Opin Virol 15:80-89

Sarde SJ, Bouwmeester K, Venegas-Molina J, David A, Boland W, Dicke M (2018) Involvement of sweet pepper CaLOX2 in jasmonate-dependent induced defence against Western flower thrips. J Integr Plant Biol 61(10):1085-1098

Steenbergen M, Abd-El-Haliem A, Bleeker P et al (2018) Thrips advisor: exploiting thrips-induced defences to combat pests on crops. J Exp Bot 69:1837-1848

Stout MJ, Workman J, Duffey SS (1994) Differential induction of tomato foliar proteins by arthropod herbivores. J Chem Ecol 20:2575-2594

Surplus S, Jordan B, Murphy A, Carr J, Thomas B, Mackerness SH (1998) Ultraviolet-B-induced responses in Arabidopsis thaliana: role of salicylic acid and reactive oxygen species in the regulation of transcripts encoding photosynthetic and acidic pathogenesisrelated proteins. Plant Cell Environ 21:685-694 
Thaler JS, Fidantsef AL, Duffey SS, Bostock RM (1999) Trade-offs in plant defense against pathogens and herbivores: a field demonstration of chemical elicitors of induced resistance. J Chem Ecol 25:1597-1609

Vänninen I, Pinto D, Nissinen A, Johansen N, Shipp L (2010) In the light of new greenhouse technologies: 1. Plant-mediated effects of artificial lighting on arthropods and tritrophic interactions. Ann Appl Biol 157:393-414

Verdaguer D, Jansen MA, Llorens L, Morales LO, Neugart S (2017) UV-A radiation effects on higher plants: exploring the known unknown. Plant Sci 255:72-81

Walters DR, Paterson L, Walsh DJ, Havis ND (2008) Priming for plant defense in barley provides benefits only under high disease pressure. Physiol Mol Plant Pathol 73:95-100

Wargent JJ, Jordan BR (2013) From ozone depletion to agriculture: understanding the role of UV radiation in sustainable crop production. New Phytol 197:1058-1076

Wargent JJ, Elfadly EM, Moore JP, Paul ND (2011) Increased exposure to UV-B radiation during early development leads to enhanced photoprotection and improved long-term performance in Lactuca sativa. Plant Cell Environ 34:1401-1413

Wargent JJ, Nelson BCW, McGhie TK, Barnes PW (2015) Acclimation to UV-B radiation and visible light in Lactuca sativa involves up-regulation of photosynthetic performance and orchestration of metabolome-wide responses. Plant Cell Environ 38:929-940

Wasternack C, Song S (2016) Jasmonates: biosynthesis, metabolism, and signaling by proteins activating and repressing transcription. J Exp Bot 68:1303-1321
Yan A, Pan J, An L, Gan Y, Feng H (2012) The responses of trichome mutants to enhanced ultraviolet-B radiation in Arabidopsis thaliana. J Photochem Photobiol B: Biol 113:29-35

Yang Y, Jiang Z, Guo J et al (2018) Transcriptomic analyses of Chrysanthemum morifolium Ramat under UV-B radiation treatment reveal variations in the metabolisms associated with bioactive components. Ind Crops Prod 124:475-486

Yao XQ, Chu JZ, He XL, Si C (2014) The effects of UV-B radiation intensity on biochemical parameters and active ingredients in flowers of Qi Chrysanthemum and Huai Chrysanthemum. Photochem Photobiol 90:1308-1313

Zavala JA, Mazza CA, Dillon FM, Chludil HD, Ballare CL (2015) Soybean resistance to stink bugs (Nezara viridula and Piezodorus guildinii) increases with exposure to solar UV-B radiation and correlates with isoflavonoid content in pods under field conditions. Plant Cell Environ 38:920-928

Zhou S, Lou YR, Tzin V, Jander G (2015) Alteration of plant primary metabolism in response to insect herbivory. Plant Physiol 169:1488-1498

Publisher's Note Springer Nature remains neutral with regard to jurisdictional claims in published maps and institutional affiliations. 